\title{
Regional uptake and release of crop carbon in the United States
}

\author{
T. O. West ${ }^{1}$, V. Bandaru ${ }^{1}$, C. C. Brandt ${ }^{2}$, A. E. Schuh ${ }^{3}$, and S. M. Ogle \\ ${ }^{1}$ Joint Global Change Research Institute, Pacific Northwest National Laboratory and University of Maryland, \\ College Park, MD 20740, USA \\ ${ }^{2}$ Biosciences Division, Oak Ridge National Laboratory, Oak Ridge, TN 37831, USA \\ ${ }^{3}$ Natural Resource Ecology Laboratory, Colorado State University, Fort Collins, CO 80523, USA
}

Received: 24 November 2010 - Published in Biogeosciences Discuss.: 21 January 2011

Revised: 23 June 2011 - Accepted: 5 July 2011 - Published: 3 August 2011

\begin{abstract}
Carbon fixed by agricultural crops in the US creates regional $\mathrm{CO}_{2}$ sinks where it is harvested and regional $\mathrm{CO}_{2}$ sources where it is released back to the atmosphere. The quantity and location of these fluxes differ depending on the annual supply and demand of crop commodities. Data on the harvest of crop biomass, storage, import and export, and on the use of biomass for food, feed, fiber, and fuel were compiled to estimate an annual crop carbon budget for 2000 to 2008. With respect to US Farm Resource Regions, net sources of $\mathrm{CO}_{2}$ associated with the consumption of crop commodities occurred in the Eastern Uplands, Southern Seaboard, and Fruitful Rim regions. Net sinks associated with the production of crop commodities occurred in the Heartland, Northern Great Plains, and Mississippi Portal regions. The national crop carbon budget was balanced to within 0.3 to $6.1 \% \mathrm{yr}^{-1}$ during the period of this analysis.
\end{abstract}

\section{Introduction}

A large amount of $\mathrm{CO}_{2}$ is fixed annually by crops through photosynthesis. Most of the fixed carbon is released in 1 to $2 \mathrm{yr}$ following harvest and subsequent decomposition or consumption and respiration by humans and livestock. Consequently, the global net annual exchange of $\mathrm{CO}_{2}$ from the uptake and release of crop carbon is near zero, with the exception of crop residues that are incorporated into soil. For this reason, changes in crop carbon stocks are not recorded in national greenhouse gas inventories, but changes in soil carbon are reported (IPCC, 2006; EPA, 2010; CCSP, 2007). While carbon dynamics associated with crop growth and harvest are

Correspondence to: T. O. West (tristram.west@pnl.gov) a global net zero, there are regional sources and sinks associated with the production, transport, and eventual release of crop carbon. Regions where large amounts of harvested carbon are exported will likely have a strong carbon uptake signal associated with crop commodity production. Regions with large imports of harvested carbon will have a large loss of carbon to the atmosphere associated with the use of crop commodities. Whether a region is a net source or sink of all carbon (i.e., cropland and non-cropland carbon) depends on the sum of fluxes from croplands, non-cropland ecosystems, and fossil fuel combustion. This analysis considers only carbon uptake and release associated with carbon fixed in US croplands.

Research is currently being conducted to monitor net carbon emissions using atmospheric $\mathrm{CO}_{2}$ concentration measurements and inverse modeling (Crevoisier et al., 2010; Lauvaux et al., 2009; Peters et al., 2007; Schuh et al., 2010), and from inventory-based modeling (EPA, 2010; Ogle et al., 2010; West et al., 2010). Comparison of these approaches allows for verification of results and future integration of methods (Nisbet and Weiss, 2010). For comparison to occur, geospatial estimates are needed on all sources and sinks in a region, including carbon uptake by crops, harvest and removal of crop carbon, and the location and amount of harvested crop carbon that is eventually released to the atmosphere. Understanding and estimating geospatial patterns in the uptake and release of carbon fixed by plants provides important information on regional carbon sources and sinks related to intensive cropland management (Ciais et al., 2007, 2010). Because these geospatial estimates require analysis of many disparate datasets, it is important to investigate whether the national crop carbon budget is balanced. The sum of crop carbon uptake, release, and sequestration should be approximately zero. 
The primary objective of this research is to geospatially locate the uptake and eventual release of carbon associated with agricultural crop commodity production and use in the US. In maintaining the definition of Net Ecosystem Production (NEP) as Net Primary Production (NPP) minus Heterotrophic Respiration (Rh), we are essentially mapping the NEP of crop ecosystems. However, unlike forest and nonagricultural ecosystems, a large amount of cropland $\mathrm{Rh}$ occurs far from where crops are grown and in areas where human and livestock respiration return the original carbon fixed by crops to the atmosphere. A secondary objective is to investigate whether the national crop carbon budget is balanced. The sum of crop carbon uptake, release through respiration and decomposition, sequestration of carbon in soils, and the ultimate use of all harvested carbon will determine the relative carbon balance. This study is the first test, to our knowledge, evaluating the carbon balance for cropland commodities in the US.

This study is limited to crop-derived carbon in an effort to account for the ultimate fate of carbon that is fixed photosynthetically, and thus is not an analysis of the carbon footprint of US crop production. Therefore, fossil-fuel emissions associated with crop production and food processing are not included. Furthermore, this study is not intended to evaluate process-based mechanisms that drive components of the crop carbon cycle (e.g., physiological plant growth modeling), but to identify all components in the US crop carbon budget and empirically estimate county-level carbon fluxes associated with these components.

\section{Components of a national crop carbon budget}

Carbon fixed in agricultural crops can be harvested and removed from the field or left to decompose in the field. Biomass carbon remaining on the field either oxidizes to $\mathrm{CO}_{2}$ or is sequestered in the soil as organic carbon. Harvested carbon is used for food, feed, fiber, or fuel. Carbon harvested for human food or livestock feed is lost through consumption and heterotrophic respiration. Carbon in biomass-derived fuel is combusted and released as $\mathrm{CO}_{2}$ and other trace gases. Carbon in fiber is sequestered for a longer time and is slowly released during the lifetime of the manufactured fiber. Carbon that is transported off the field and not used for food, feed, fiber, or fuel may be exported, stored in crop biomass reserves, used for crop seed production, or may enter into the municipal waste stream. The following sections provide details on the methods used to estimate each component of the US crop carbon budget. The temporal resolution of the estimates is annual, and the spatial resolution is the county geopolitical unit. While methods for estimating crop NPP, soil carbon change, and human carbon emissions from inventory data have been documented previously, methods for estimating total carbon emissions from livestock have not. As such, greater emphasis is placed on our method for esti- mating livestock emissions in Sect. 2.5. This analysis is the first time that all of these datasets have been brought together to estimate net annual flux associated with crop-derived carbon.

In our analysis, we differentiate between the national crop carbon budget and the county level net carbon flux estimates. The national budget includes all available data needed to estimate the production and ultimate use of crop carbon, thereby enabling estimates of where crop-derived carbon is emitted and the quantity of emissions. The geospatial county flux estimates differ in that they include only vertical fluxes that occur within geopolitical county boundaries with the purpose of providing crop-derived net carbon flux to the atmosphere. Livestock emissions are handled differently between the two methods because of data availability issues and differing objectives for each exercise. Additional details on livestock emissions are provided in Sect. 2.5.

\subsection{Net primary production, harvest, and decomposition}

Net primary production of crops is based on county-scale mean crop yield data from the US Department of Agriculture (USDA), National Agricultural Statistics Service (NASS) (USDA, 2010a). Absent county level data were gap-filled with available district level data. District level statistics in the inventory data are reported in aggregate for non-reporting counties. We, therefore, disaggregate and distribute the combined district data equally to remaining counties in each district that has no reported data. In this way, we maintain a more complete inventory of total national crop statistics, compared to using county level data only.

Harvest indices, root:shoot ratios, and estimated dry weight values for each crop were used to convert crop yields to NPP. The conversion factors used in this analysis have been documented by West et al. (2010). A carbon content of $45 \%$ for crop biomass was used in our estimates of NPP for all crops. NPP was estimated for 17 crops: corn, soybean, oats, barley, wheat, sunflower, hay, sorghum, cotton, rice, peanuts, potatoes, sugarbeets, sugarcane, tobacco, rye, and beans. The sum of these crops represented $99 \%$ of total US crop production in 2008 (USDA, 2010a). Estimates of crop yields were used to represent the amount of carbon removed and transported off the farm field. Crop residue remaining on the field, along with belowground biomass, either decomposes or is sequestered in situ as soil organic carbon. Carbon in crop residue and belowground biomass that is not sequestered in soil is estimated to be decomposed in the same year.

\subsection{Soil carbon}

Empirical relationships between land management and soil carbon change (West et al., 2008) were used to estimate annual changes in soil carbon based on inventory statistics for 
planted crops, tillage intensity per crop, and initial soil carbon content. While this analysis focuses on carbon dynamics between 2000 and 2008, estimates of soil carbon change were calculated from 1980 to 2008 in order to capture longerterm impacts on soil carbon pools from a 20 -yr history of changes in crop rotations and tillage intensity. Tillage intensity data are based on bi-annual surveys conducted by the Conservation Technology Information Center (CTIC, 2007). Years without data (i.e., odd years between 2000 and 2004) were imputed by interpolating between prior and subsequent years, and by estimating trends in adoption of conservation tillage practices from historical data. Tillage intensities were aggregated into three classes for soil carbon change estimation: no tillage, reduced tillage including mulch tillage and ridge tillage, and conventional tillage. Changes in soil carbon were estimated for agricultural crops only and do not include soil carbon change occurring on croplands set aside in conservation programs. We do not include soil carbon change associated with set-aside lands, because our analysis is focused on the ultimate fate of carbon fixed by agricultural crops. Changes in soil carbon are estimated to a $30 \mathrm{~cm}$ depth, commensurate with methods described by West et al. (2008).

\subsection{Lateral transport of carbon}

Carbon that is removed from the farm field can be used locally as livestock feed or can be transported to distant locations for feed, food, fiber, and fuel uses. With the exception of fiber and sequestration in landfills, the majority of crop carbon is released back to the atmosphere. The location where this carbon is released is critical for estimating regional carbon budgets (Ciais et al., 2007). Estimating the ultimate release of crop carbon depends largely on how and where the carbon is used. Our analysis uses humans and livestock populations as proxies for where crop carbon is ultimately transported and released to the atmosphere. When a region harvests a given unit of carbon, a portion of that carbon will be emitted within the region based on human and livestock populations, and the rest will be either emitted elsewhere in the US, exported, or stored in carryover reserves or in fiber products.

\subsection{Human food}

Estimates of carbon consumption and carbon dioxide release by humans are based on per capita food consumption in the United States (West et al., 2009) (Table 1). Food commodity intake data from the Food Commodity Intake Database (EPA, 2000) were averaged for each age cohort and gender. All food commodities were adjusted to dry weight and converted to carbon using 0.45 as the fraction of dry weight that is carbon. Annual county population demographic data were obtained by US Census Bureau (2010) and summed by age and gender. While we have the ability to track all carbon releases from respiration, excretion, and flatus (West et al.,
Table 1. Consumption and release of carbon by humans.*

\begin{tabular}{lcccc}
\hline $\begin{array}{l}\text { Age } \\
\text { Group }\end{array}$ & Gender & $\begin{array}{c}\text { Food } \\
\text { consumption }\end{array}$ & Expiration & $\begin{array}{c}\text { Excrement } \\
\text { and flatus }\end{array}$ \\
\cline { 3 - 5 } & & \multicolumn{3}{c}{$\left(\mathrm{kg} \mathrm{Capita}^{-1} \mathrm{yr}^{-1}\right)$} \\
\hline$<5$ & M & 39.3 & 34.6 & 4.7 \\
$<5$ & $\mathrm{~F}$ & 36.2 & 31.9 & 4.3 \\
$5-9$ & $\mathrm{M}$ & 55.8 & 49.1 & 6.7 \\
$5-9$ & $\mathrm{~F}$ & 51.0 & 44.9 & 6.1 \\
$10-14$ & $\mathrm{M}$ & 69.3 & 61.0 & 8.3 \\
$10-14$ & $\mathrm{~F}$ & 53.4 & 47.0 & 6.4 \\
$15-39$ & $\mathrm{M}$ & 81.4 & 71.6 & 9.8 \\
$15-39$ & $\mathrm{~F}$ & 52.6 & 46.3 & 6.3 \\
$40-59$ & $\mathrm{M}$ & 74.8 & 65.8 & 9.0 \\
$40-59$ & $\mathrm{~F}$ & 50.3 & 44.3 & 6.0 \\
$60-74$ & $\mathrm{M}$ & 68.3 & 60.1 & 8.2 \\
$60-74$ & $\mathrm{~F}$ & 46.8 & 41.2 & 5.6 \\
$75-84$ & $\mathrm{M}$ & 57.7 & 50.8 & 6.9 \\
$75-84$ & $\mathrm{~F}$ & 48.2 & 42.4 & 5.8 \\
$>85$ & $\mathrm{M}$ & 51.9 & 45.7 & 6.2 \\
$>85$ & $\mathrm{~F}$ & 41.1 & 36.2 & 4.9 \\
\hline
\end{tabular}

* From West et al. (2009). Data on human carbon emissions per county are archived at http://cdiac.ornl.gov/carbonmanagement/humanemissions.

2009), we used carbon consumption in this analysis as an estimate of total carbon release to the atmosphere. We did this to simplify the accounting procedure and because the majority of all emissions, even those from excretion that enter the waste treatment facilities, typically occur within the same county.

Additional carbon is lost between harvest and consumption due to food processing and food waste. This carbon is accounted for in the crop carbon budget as food loss. Food loss occurs at the retail and consumer levels in the food preparation industry, with the greatest loss occurring at the consumer level (Kantor et al., 1997). Total food loss for grains, meats, fruits, vegetables, and dairy is $30 \%, 54 \%$, $51 \%, 57 \%$, and $29 \%$, respectively (USDA, 2010b).

\subsection{Livestock feed}

Livestock feed was calculated using a method similar to that used for estimating human emissions. Using this method, emissions are based on the amount of feed consumed and the population of livestock species. The amount of feed consumed and the associated emissions of $\mathrm{CH}_{4}$ are based on IPCC (1996) and EPA (2010). Dry weight and carbon content of livestock feed were used to estimate total carbon intake (Table 2). Carbon in the solid form is released as manure and milk production, methane is released from enteric fermentation and manure management, and carbon dioxide is released from livestock expiration. Carbon emissions from methane production are in units of carbon and have not been multiplied by the global warming potential of methane. $\mathrm{CO}_{2}$ 
Table 2. Consumption and release of carbon by livestock.*

\begin{tabular}{lrrrrr}
\hline Animal & $\begin{array}{r}\text { Feed } \\
\text { Consumption }\end{array}$ & Expiration & Excrement & $\begin{array}{r}\text { Enteric fermentation } \\
\text { and flatus }\end{array}$ & $\begin{array}{r}\text { Milk } \\
\text { production }\end{array}$ \\
\cline { 2 - 6 } & \multicolumn{5}{c}{$\left(\mathrm{kg} \mathrm{Chead}^{-1} \mathrm{yr}^{-1}\right)$} \\
\hline Dairy cow & 2513.0 & 960.7 & 1028.3 & 88.5 & 435.5 \\
Non-dairy cow & 1070.4 & 610.7 & 424.4 & 35.3 & - \\
Swine & 108.6 & 52.0 & 55.4 & 1.1 & - \\
Poultry & 41.9 & 24.4 & 17.5 & 0.0 & - \\
Sheep & 167.5 & 98.5 & 63.1 & 6.0 & - \\
Goat & 117.9 & 70.0 & 44.2 & 3.8 & - \\
Horse & 924.6 & 609.7 & 301.3 & 13.5 & - \\
Dog & 25.9 & 15.0 & 10.4 & 0.5 & - \\
Cat & 13.0 & 7.5 & 5.2 & 0.3 & - \\
\hline
\end{tabular}

* Based on IPCC $(1996,2006)$ and EPA (2010). Average feed estimates for dogs and cats are from suggested daily serving size of respective foods. Data on livestock emissions per county are archived at http://cdiac.ornl.gov/carbonmanagement/livestockemissions.

emissions from livestock are not usually estimated in national emissions inventories, because the respired $\mathrm{CO}_{2}$ is a cyclical release of carbon that was previously taken up by plants and, as such, results in net zero emissions with respect to the global atmosphere. Emissions of $\mathrm{CO}_{2}$ are estimated here as the remainder of consumed carbon that is not accounted for by enteric fermentation, manure, and milk production (Table 2). The annual mass of livestock available for use in the human food supply is from the USDA Food Availability Data (USDA, 2009a).

Annual state and county livestock population estimates were obtained from the USDA NASS (USDA, 2010a). Livestock data from the 1987, 1992, 1997, 2002, and 2007 Agricultural Census were used to supplement the NASS annual data. Livestock populations in our emissions estimates include beef cows, dairy cows, swine, turkey, chickens, sheep, and goats. Livestock population data in the USDA NASS data are absent for some regions in some years. In these cases, population data at the state or district level were distributed to the county level based on estimates from previous years and on the fraction of livestock per county derived from the Agricultural Census.

The county level flux estimates in our analysis include total carbon emissions from livestock, which consist of consumption and respiration of both crop carbon and pasture carbon. Consumption of crop carbon and pasture carbon cannot be differentiated at the county level using currently available inventory data. However, we excluded non-crop carbon (i.e., pasture carbon) from the national crop carbon budget in an effort to focus on the ultimate fate of crop-derived carbon and to balance the crop carbon budget. Crop carbon for livestock feed that is included in the national crop carbon budget consists of feed grains (i.e., corn, sorghum, barley, and oats), wheat used for feed, hay, corn silage, and sorghum silage (USDA, 2009b, 2010a).
Feed consumption by horses and household pets (i.e., dogs and cats) are also included in the livestock category. Consumption and release of carbon by horses follows IPCC guidelines (IPCC, 2006). Consumption and release by dogs and cats were estimated using suggested daily servings for dogs and cats of 216 and $108 \mathrm{~g} \mathrm{day}^{-1}$, respectively, of bagged pet food. Water weight and carbon content were estimated to be $10 \%$ and $45 \%$, respectively. Horse, dog, and cat populations were obtained from AVMA (2007). Horse, dog, and cat feed are hereinafter collectively included in livestock feed.

\subsection{Commodity fiber}

The harvested portion of cotton and tobacco is removed from crop fields and does not enter the livestock feed or human food supply. The portion that is exported is included in the US export estimate. Emissions of carbon from fiber are not considered in this analysis. However, cotton fibers will eventually be emitted as $\mathrm{CO}_{2}$ during decomposition of the fiber, and a portion of the tobacco will be emitted as it is burned in tobacco products. While fiber is not included in the geospatial, county-level net flux estimate, we include it in the national crop carbon budget for the purpose of balancing the carbon budget.

\subsection{Biomass for fuel, import, and export}

Biomass for fuel currently includes corn grain used for ethanol and soybean used for biodiesel (USDA, 2010c, d). Agricultural import and export quantities are from USDA (2010e). Dry weight and carbon content used in estimates of biomass for fuel, imports, and exports are the same as those used in carbon estimates for NPP. 
Table 3. Annual US crop carbon budget.

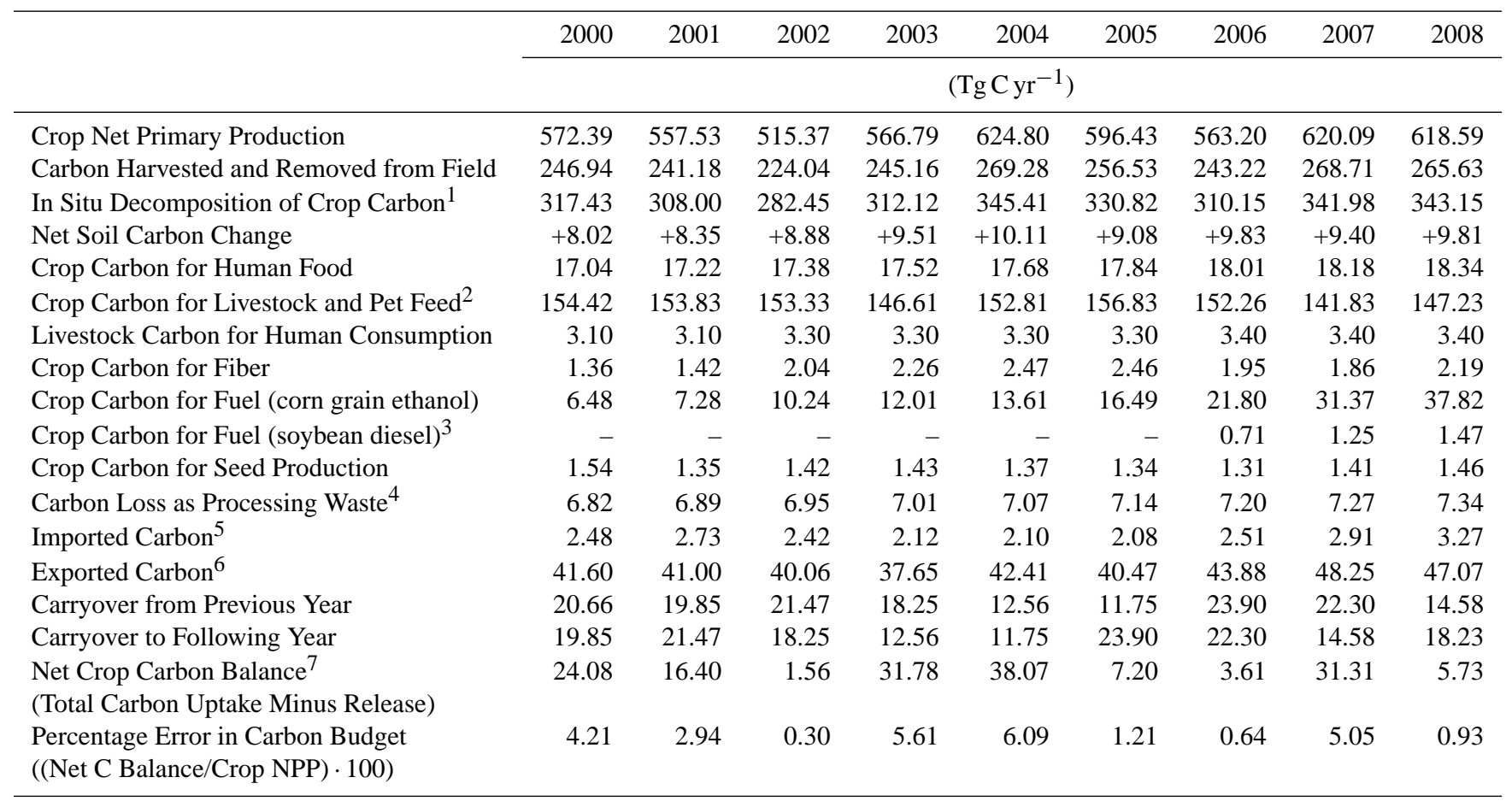

1 All decomposition is estimated here to occur within the same growing year.

${ }^{2}$ Biomass carbon for livestock feed includes only carbon derived from cropland commodities for purposes of balancing the crop carbon budget. Total biomass carbon from croplands and pasturelands that is consumed and released by livestock is included in Table 4 for estimates of total net vertical fluxes of carbon in respective geographic regions.

${ }^{3}$ Data for soybean diesel are available only from 2006 to present (USDA, 2010d).

${ }^{4}$ Carbon loss includes carbon removed from the food supply during preparation of crop and livestock commodities for retail sale, preparation for final consumption, and waste following final consumption.

5 Carbon imported into the US food supply.

6 Carbon exported out of the US food supply.

7 Net Crop Carbon Balance is intended to account for the ultimate use of all harvested crop biomass and its release to the atmosphere as CO 2 . As such, Net Crop Carbon Balance $=$ Crop Net Primary Production - Decomposition of Crop Carbon - Net Soil Carbon Change - Crop Carbon for Human Food - Crop Carbon for Livestock and Pet Feed + Livestock Carbon for Human Consumption - Crop Carbon for Fiber - Crop Carbon for Fuel - Crop Carbon for Seed Production - Carbon Loss as Processing Waste + Imported Carbon - Exported Carbon + Carryover from Previous Year - Carryover to Following Year.

\section{Results and discussion}

Estimating net uptake and release of crop-derived carbon is important for estimating regional carbon sources and sinks, and for comparison to atmospheric measurements and modeling. Constructing a US crop carbon budget is needed to confirm and constrain estimates of net carbon uptake and release from cropland production and consumption. Our results indicate that total NPP on US croplands ranges from 515-625 $\mathrm{Tg} \mathrm{C} \mathrm{yr}^{-1}$ between 2000 and 2008 (Table 3). This estimate includes haylands and is consistent with past estimates of $400-600 \mathrm{Tg} \mathrm{C} \mathrm{yr}^{-1}$ between 1972 and 2001 by Hicke et al. (2004) and a mean $620 \mathrm{Tg} \mathrm{C} \mathrm{yr}^{-1}$ between 1982 and 1998 by Lobell et al. (2002). The amount of biomass removed from farm fields ranges from $224-269{\mathrm{Tg} \mathrm{C} \mathrm{yr}^{-1}}^{-1}$ Annual changes in national crop NPP and biomass harvest are influenced by policy (e.g., Farm and Energy Bills), weather (e.g., flooding and drought), and commodity prices and supply (Nelson et al., 2009). The annual amount of carbon taken up by crops, as estimated here, is roughly $37 \%$ of total US annual $\mathrm{CO}_{2}$ emissions (EPA, 2010). While most of this carbon is emitted back to the atmosphere resulting in net zero emissions, our calculations indicate the magnitude of carbon that is being managed and transported around vast areas.

Changes in soil carbon include changes on planted and harvested croplands, and do not include changes on grasslands, pastures, or set-aside lands. Net changes in soil car-

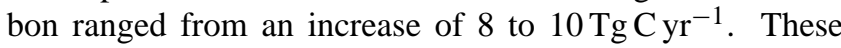
estimates are consistent with past estimates that consider the trend in adoption of conservation tillage practices in the US (Ogle et al., 2010; Tan et al., 2006; West et al., 2008). The remainder of on-site carbon is released through decomposition. Harvested biomass is released offsite as $\mathrm{CO}_{2}$ through the consumption or use of crop commodities.

The four primary uses of agricultural commodities are food, feed, fiber, and fuel. The majority of harvested biomass is used to feed livestock (Fig. 1). Following the processing

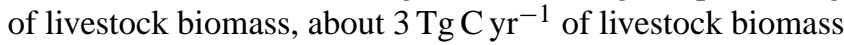




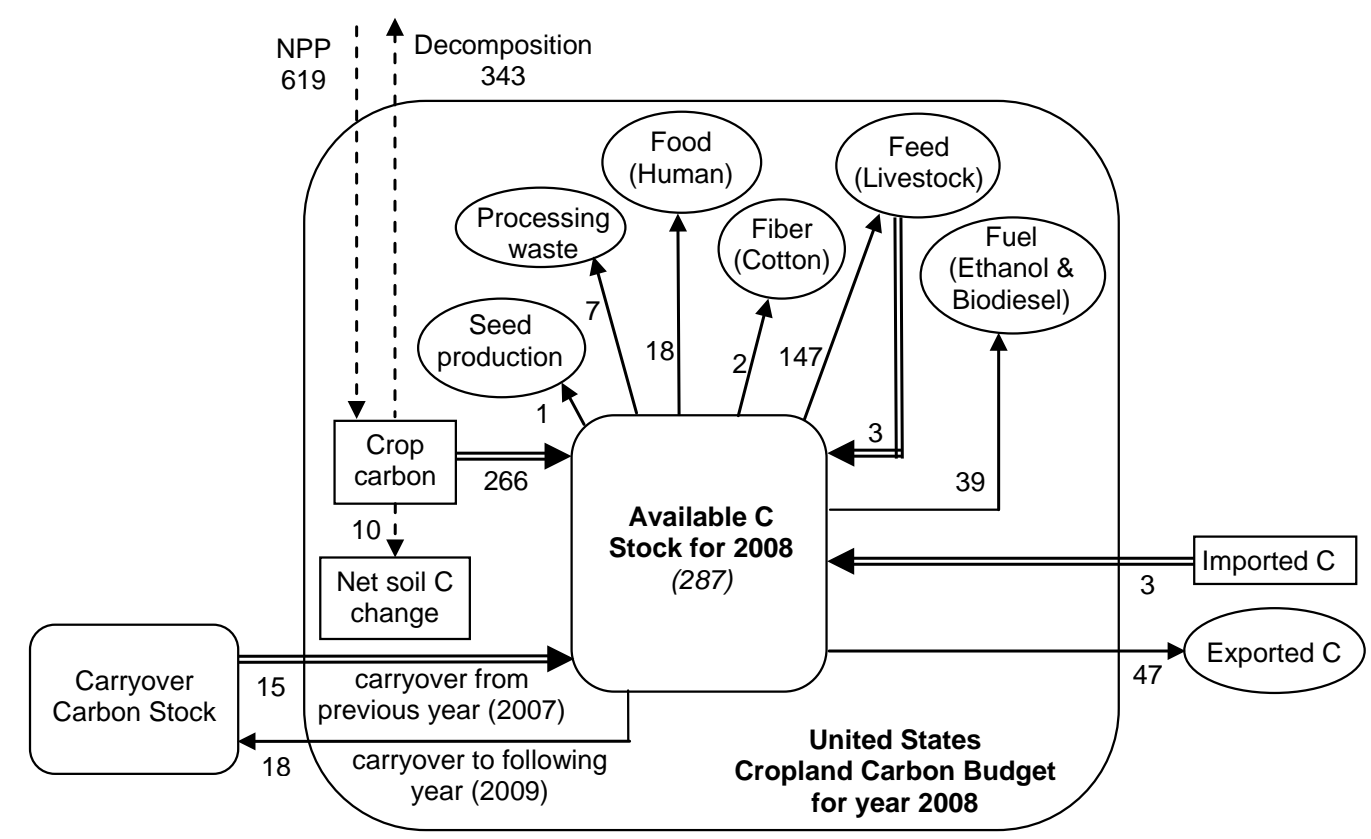

Fig. 1. Cropland carbon budget for the contiguous US. This budget represents the movement of annual crop carbon into, out of, and within the US for the year 2008. Double arrows represent inputs to the annual crop carbon stock that are available for food, feed, fiber, and fuel; single arrows represent flows of carbon that lessen the available crop carbon stock; and dashed arrows represent initial photosynthetic production of crop carbon and estimated net soil carbon accumulation. Ellipses represent end uses of crop carbon. All units are in $\mathrm{Tg} \mathrm{C} \mathrm{yr}^{-1}$.

is introduced into the human food supply. Horses, dogs, and cats are also included in the livestock estimate and together consume about $13 \mathrm{TgC}^{-1}$. Food for humans increased from 17 to $18 \mathrm{Tg} \mathrm{Cyr}^{-1}$ during the study period. Fiber includes cotton, and the amount of harvested cotton increased from 2000 to 2005 , but declined by over $0.5 \mathrm{Tg} \mathrm{C} \mathrm{yr}^{-1}$ from 2005 to 2007.

Biomass used for fuel includes corn grain for ethanol and soybean oil for biodiesel. Total biomass for fuel increased from 6.5 to $39.3 \mathrm{Tg} \mathrm{Cyr}^{-1}$ between 2000 and 2008 (Table 3). While use of soybean for diesel doubled from 0.7 to $1.5 \mathrm{Tg} \mathrm{C} \mathrm{yr}^{-1}$ between 2006 and 2008 , it is a small fraction of the biomass used for fuel $(<4 \%)$. Use of corn grain for ethanol has increased steadily since 1980 (USDA, 2007). Larger annual increases have occurred since 2005 with the largest increase of $9.6 \mathrm{Tg} \mathrm{C}$ occurring in 2007. The diversion of harvested corn grain for ethanol production in 2007 and 2008 decreased the amount of biomass available for livestock feed and decreased carryover in grain reserves (Fig. 2).

Combining estimates of crop NPP, harvested biomass, and all end uses of biomass allows for development of a national crop carbon budget. A balanced carbon budget should theoretically result in net zero crop carbon exchange with the atmosphere over a $1-2 \mathrm{yr}$ period, assuming we have correctly tracked all carbon uptake and release, including imports and exports, and regardless of where the carbon is ultimately released. We do not completely close the budget for any year in our analysis. The annual imbalance surrounding our bud-
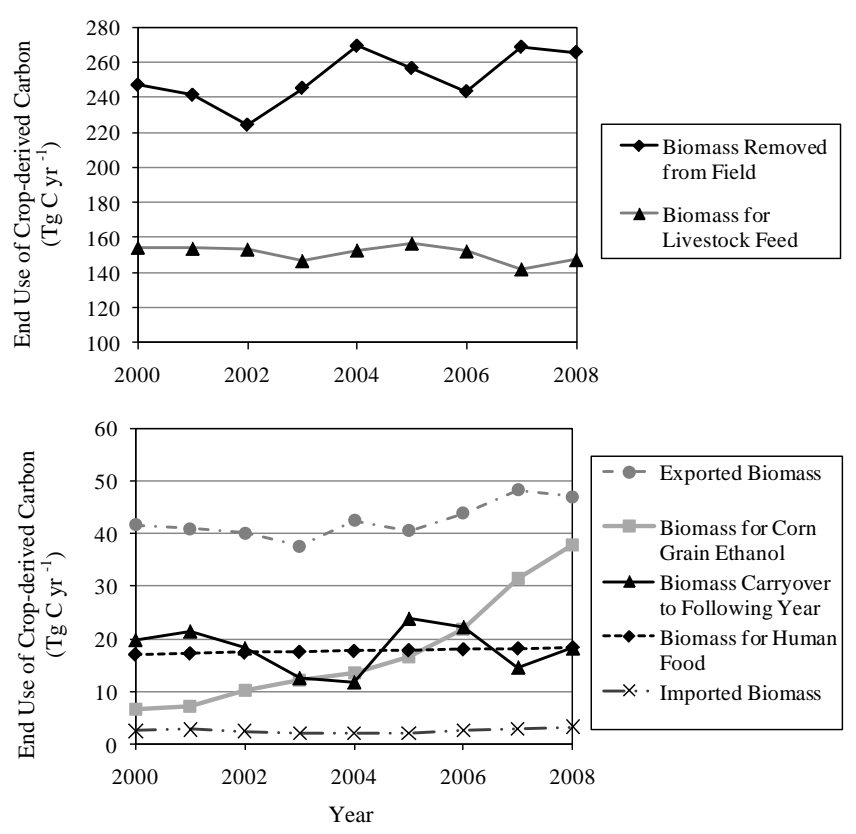

Fig. 2. Components of the US crop carbon budget from 2000 to 2008. Some components of the US crop carbon budget are shown here to illustrate where predominant changes in the budget occurred between 2000 and 2008. See Table 3 for all components. 


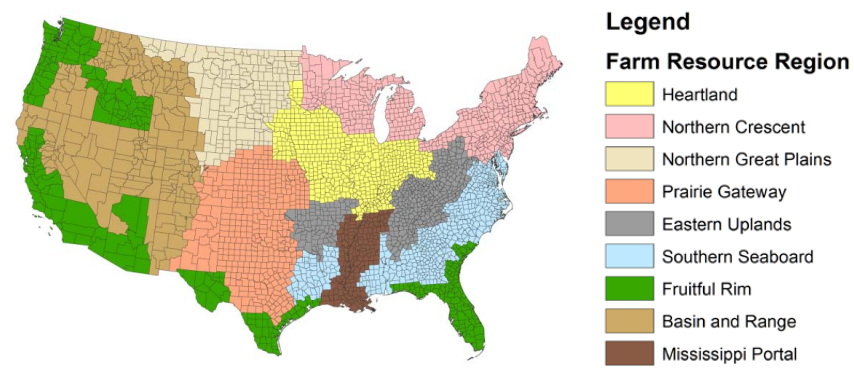

Fig. 3. Farm Resource Regions were defined by USDA (2000) to represent geographic specialization in production of US farm commodities. These regions are used to aggregate county-level results in our analysis.

get ranges from 0.3 to $6.1 \%$ between 2000 and 2008 (Table 3). This imbalance is relatively small, indicating that the final use of most of the harvested carbon in the US is accounted for.

Distributing the national crop carbon budget on a county basis allows us to identify regions where crop commodities in the US are predominantly a source or sink for atmospheric carbon dioxide. We aggregated data by county and by USDA Farm Resource Regions (USDA, 2000) (Fig. 3). While many components of the national budget can be mapped, we focused on components that influence the vertical flux of carbon. These components include the amount of biomass harvested, consumption of biomass and release of $\mathrm{CO}_{2}$ by humans and livestock, and the net county-level exchange of crop-derived carbon (Fig. 4). The estimate of net carbon exchange includes annual crop NPP, harvest and removed carbon, in situ decomposition, changes in soil carbon, and emissions from livestock and humans. Biomass exports are released as $\mathrm{CO}_{2}$ outside of the US, as illustrated by Ciais et al. (2007). Biomass imports are included in estimates of regional net emissions through the consumption of biomass by humans and livestock. Carbon dioxide released by combustion of biomass-based diesel and ethanol is tracked in separate fossil fuel budgets that include data from the transportation sector (Gurney et al., 2009).

Harvest of cropland biomass and transport to other regions is the dominant process leading to a net carbon uptake in some regions, which has been confirmed by atmospheric measurements (Crevoisier et al., 2010; Peters et al., 2007). The geographic pattern of biomass removal is consistent with previous analyses of cropland biomass growth. However, the percentage of harvested biomass changes substantially based on the crop planted. For example, nearly all above-ground biomass is harvested in fields planted for hay and silage. This is in contrast to crops that are grown for grain only. Because of this difference, datasets on biomass removal are not directly comparable to datasets on biomass growth or NPP.
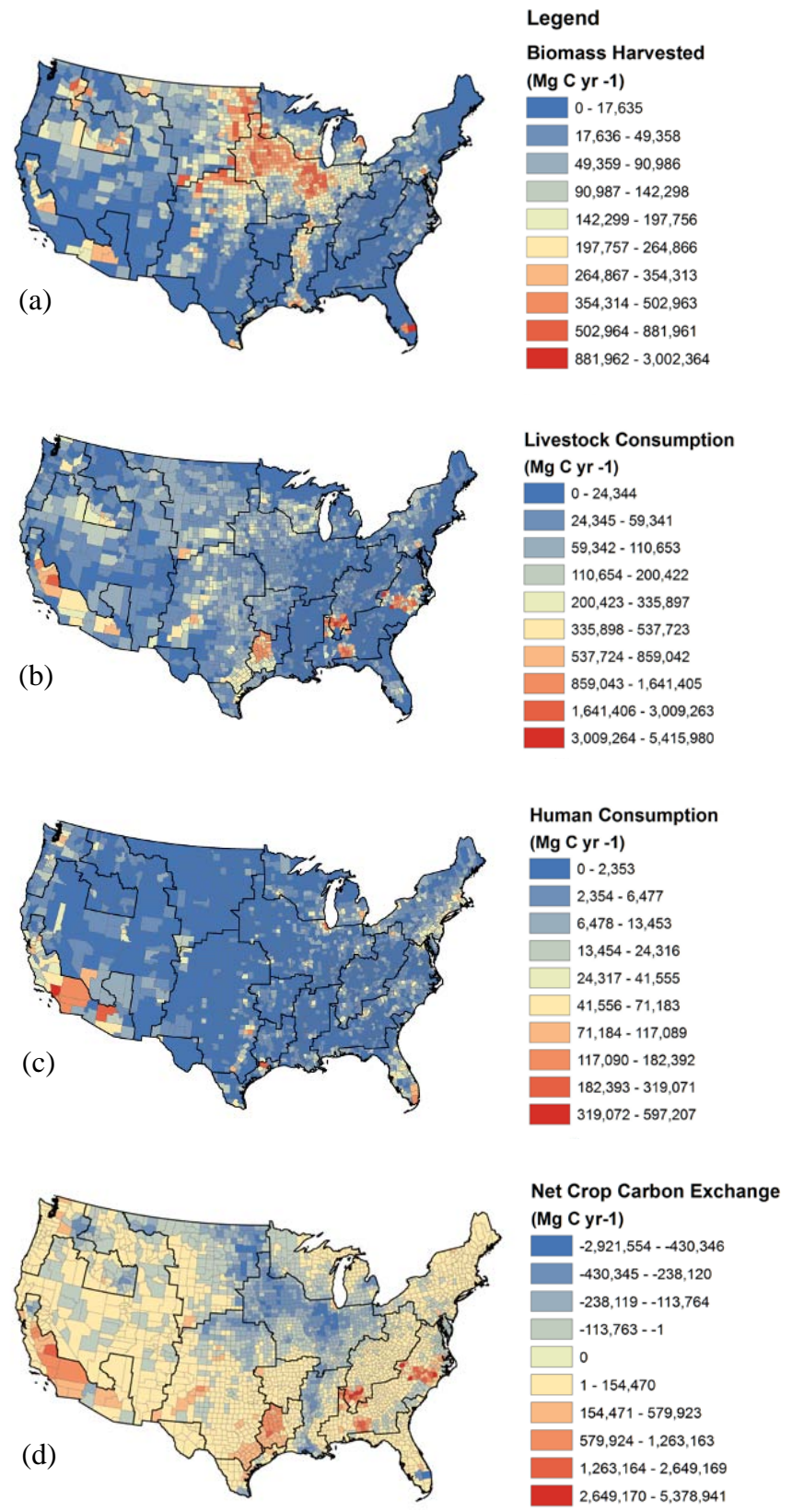

Fig. 4. Harvested biomass, approximate release of biomass carbon from humans and livestock, and the geographic net exchange of crop carbon for 2008. Harvested biomass (a) is removed from the field and released as $\mathrm{CO}_{2}$ by livestock and humans (b and $\mathbf{c}$ ). Net exchange of crop carbon (d) is the sum of net carbon uptake by crops, net change in soil carbon, and the release of carbon through biomass decomposition and the consumption and respiration by livestock and humans. Net carbon exchange estimates represent annual vertical fluxes within each county. 
Table 4. Regional net carbon exchange of crop-derived carbon.*

\begin{tabular}{|c|c|c|c|c|c|c|c|c|c|c|}
\hline \multicolumn{2}{|c|}{ Farm Resource Region } & 2000 & 2001 & 2002 & 2003 & 2004 & 2005 & 2006 & 2007 & 2008 \\
\hline 1 & Heartland & -86.95 & -85.58 & -79.94 & -85.81 & -106.20 & -95.44 & -95.23 & -101.38 & -97.88 \\
\hline 2 & Northern Crescent & 2.05 & 4.96 & 3.64 & 2.53 & 1.66 & 2.33 & 2.08 & 3.35 & -5.00 \\
\hline 3 & Northern Great Plains & -13.86 & -12.36 & -8.68 & -15.35 & -15.19 & -17.14 & -10.82 & -18.71 & -19.17 \\
\hline 4 & Prairie Gateway & 1.97 & -0.97 & 5.04 & -0.10 & -3.06 & -1.85 & 5.32 & -3.12 & -2.17 \\
\hline 7 & Fruitful Rim & 7.67 & 9.86 & 9.37 & 9.33 & 9.57 & 11.37 & 11.70 & 11.14 & 13.11 \\
\hline 8 & Basin and Range & -0.02 & 0.22 & 0.46 & -0.22 & -0.74 & -0.95 & -0.33 & -0.35 & 0.64 \\
\hline 9 & Mississippi Portal & -9.65 & -10.69 & -10.73 & -10.96 & -10.80 & -9.44 & -9.33 & -12.49 & -12.12 \\
\hline US & Total & -17.53 & -56.71 & 4.89 & -17.61 & -87.10 & -26.32 & 21.97 & -2.12 & -14.07 \\
\hline
\end{tabular}

* Negative values indicate a net regional sink of crop-derived carbon; positive values indicate a net source of crop-derived carbon. Emissions from livestock include both crop-derived and pasture-derived carbon for more complete vertical flux estimates per region (see text for additional detail). Estimates of net carbon exchange consist of vertical fluxes only and do not include the eventual release of horizontally displaced carbon, such as export, processing waste, biomass carryover, etc. (see Table 3 for a list of all carbon budget components).

Release of consumed carbon by livestock is a dominant source of carbon emissions in several farm resource regions, including the Northern Crescent, Northern Great Plains, Prairie Gateway, Southern Seaboard, and Fruitful Rim. While livestock emissions do occur in the Midwest where much crop biomass is harvested, a large amount of biomass carbon is transported to the eastern, southern, and western US where it is consumed by livestock and released as $\mathrm{CO}_{2}$ and $\mathrm{CH}_{4}$ (Fig. 4b).

Consumption by humans (Fig. 4c) is relatively small when considered within the national budget (Fig. 1), but it constitutes a considerable fraction of net emissions in highly populated regions and counties. The geospatial distribution of concentrated human populations and their associated food intake is not as vast as livestock, but the carbon uptake and release is of the same magnitude of livestock where concentrated human populations exist.

Combining the aforementioned components together with changes in soil carbon provides a dataset of net carbon exchange resulting from the uptake, transport, and release of crop-derived carbon in the US (Fig. 4d). There is a net uptake of carbon associated with crop commodities in several farm resource regions, including the Heartland, Northern Great Plains, and Mississippi Portal regions (Table 4). A net release of crop-derived carbon occurs in the Eastern Uplands, Southern Seaboard, and Fruitful Rim. The Prairie Gateway and Basin and Range regions oscillate between a positive and negative annual net carbon exchange, with respect to cropderived carbon.

\section{Conclusions}

Management of US croplands changes over time with changes in technology and with demand for crop commodities. Combining multiple datasets enables us to understand how the US agricultural system is changing and how these changes influence regional carbon dynamics. Over a 9-yr period, carbon uptake by crops in the US varied by more than $100 \mathrm{TgC} \mathrm{yr}^{-1}$, influencing regional carbon exchange between the atmosphere and land surface. Changes in demand for crop commodities resulted in changes in the distribution of carbon across the regions. This was particularly evident with the reallocation of $10 \mathrm{Tg} \mathrm{C} \mathrm{yr}^{-1}$ of corn grain in 2007 from livestock, exports, and grain reserves to ethanol fuel production. This reallocation resulted in a geospatial redistribution of $\mathrm{CO}_{2}$ release to the atmosphere.

Net sources of $\mathrm{CO}_{2}$ associated with the consumption of crop commodities occurred in the Eastern Uplands, Southern Seaboard, and Fruitful Rim farm resource regions. Net sinks associated with the production of crop commodities occurred in the Heartland, Northern Great Plains, and Mississipi Portal regions. Considering all components of the US crop carbon budget resulted in the budget being balanced within 0.3 to $6.1 \% \mathrm{yr}^{-1}$ of total crop NPP during the period of this analysis. Through this research, we have generated geospatial datasets from 2000 to 2008 that represent the geospatial uptake and release of carbon associated with crop commodities in the US. These spatially distributed data can be used for regional carbon budget analyses, comparison with mechanistic biogeochemistry models, and as constraints to atmospheric inversion modeling. 
Acknowledgements. We gratefully acknowledge the National Aeronautics and Space Agency, Earth Sciences Division for support through the North American Carbon Program, Mid-Continent Intensive Campaign (Agreement No. NNX08AK08G). We thank the Carbon Dioxide Information Center for archiving results from this analysis at http://cdiac.ornl.gov/carbonmanagement.

Edited by: J. Yu

\section{References}

AVMA: U.S. Pet Ownership and Demographics Sourcebook, American Veterinary Medical Association, Washington, DC, 2007.

CCSP: The first state of the carbon cycle report (SOCCR): The North American carbon budget and implications for the global carbon cycle. A report by the U.S. Climate Change Science Program and the Subcommittee on Global Change Research, edited by: King, A. W., Dilling, L., Zimmerman, G. P., Fairman, D. M., Houghton, R. A., Marland, G., Rose, A. Z., and Wilbanks, T. J., National Oceanic and Atmospheric Administration, National Climatic Data Center, Asheville, North Carolina, USA, 2007.

Ciais, P., Bousquet, P., Freibauer, A., and Naegler, T.: Horizontal displacement of carbon associated with agriculture and its impacts on atmospheric $\mathrm{CO}_{2}$, Global Biogeochem. Cy., 21, GB2014, doi:10.1029/2006GB002741, 2007.

Ciais, P., Wattenbach, M., Vuichard, N., Smith, P., Piao, S. L., Don, A., Luyssaer, S., Janssens, I. A., Bondeau, A., Dechow, R., Leip, A., Smith, P. C., Beer, C., Van Der Werf, G. R., Gervois, S., Van Oost, K., Tomelleri, E., Freibauer, A., Schulze, E. D., and Carboeurope Synthesis Team: The European carbon balance. Part 2: croplands, Glob. Change Biol., 16, 1409-1428, 2010.

Crevoisier, C., Sweeney, C., Gloor, M., Sarmiento, J. L., and Tans, P. P.: Regional US carbon sinks from three-dimensional atmospheric $\mathrm{CO}_{2}$ sampling, P. Natl. Acad. Sci. USA, 107, 1834818353, 2010.

CTIC: Crop residue management survey, Conservation Technology Information Center, West Lafayette, Indiana, USA, 2007.

EPA: Food commodity intake database (FCID), United States Environmental Protection Agency, Office of Pesticide Programs, Washington DC, 2000.

EPA: Inventory of U.S. Greenhouse Gas Emissions and Sinks: 1990-2008, EPA 430-R-10-006, United States Environmental Protection Agency, Washington DC, 2010.

Gurney, K. R., Mendoza, D. L., Zhou, Y., Fischer, M. L., Miller, C. C., Geethakumar, S., and De La Rue Du Can, S.: High resolution fossil fuel combustion $\mathrm{CO}_{2}$ emissions fluxes for the United States, Environ. Sci. Technol., 43, 5535-5541, 2009.

Hicke, J. A., Lobell, D. B., and Asner, G. P.: Cropland area and net primary production computed from 30 years of USDA agricultural harvest data, Earth Interact., 8, 1-20, 2004.

IPPC: Intergovernmental Panel on Climate Change: Revised: 1996 IPCC Guidelines for National Greenhouse Gas Inventories, Vol. 3, Hadley Centre: Bracknell, United Kingdom, 1996.

IPPC: Intergovernmental Panel on Climate Change: 2006 IPCC Guidelines for National Greenhouse Gas Inventories, Vol. 4, Cropland, Institute for Global Environmental Strategies, Kanagawa, Japan, 2006.
Kantor, L. S., Lipton, K., Manchester, A., and Oliveira, V.: Estimating and Addressing America's Food Losses, Food Review, United States Department of Agriculture, Economic Research Service, 2-12, 1997.

Lauvaux, T., Gioli, B., Sarrat, C., Rayner, P. J., Ciais, P., Chevallier, F., Noilhan, J., Miglietta, F., Brunet, Y., Ceschia, E., Dolman, H., Elbers, J. A., Gerbig, C., Hutjes, R., Jarosz, N., Legain, D., and Uliasz, M.: Bridging the gap between atmospheric concentrations and local ecosystem measurements, Geophys. Res. Lett., 36, L19809, doi:10.1029/2009GL039574, 2009.

Lobell, D. B., Hicke, J. A., Asner, G. P., Field, C. B., Tucker, C. J., and Los, S. O.: Satellite estimates of productivity and light use efficiency in United States agriculture, 1982-98, Glob. Change Biol., 8, 722-735, 2002.

Nelson, R. G., Hellwinckel, C. M., Brandt, C. C., West, T. O., De La Torre Ugarte, D. G., and Marland, G.: Energy use and carbon dioxide emissions from cropland production in the United States, 1990-2004, J. Environ. Qual., 38, 418-425, 2009.

Nisbet, E. and Weiss, R.: Top-down versus bottom-up, Science, 328, 1241-1243, 2010.

Ogle, S. M., Breidt, F. J., Easter, M., Williams, S., Killian, K., and Paustian, K.: Scale and uncertainty in modeled soil organic carbon stock changes for US croplands using a process-based model, Glob. Change Biol., 16, 810-822, 2010.

Peters, W., Jacobson, A. R., Sweeney, C., Andrews, A. E., Conway, T. J., Masarie, K., Miller, J. B., Bruhwiler, L. M. P., Pétron, G., Hirsch, A. I., Worthy, D. E. J., van der Werf, G. R., Randerson, J. T., Wennberg, P. O., Krol, M. C., and Tans, P. P.: An atmospheric perspective on North American carbon dioxide exchange: CarbonTracker, P. Natl. Acad. Sci. USA, 104, 18925-18930, 2007.

Schuh, A. E., Denning, A. S., Corbin, K. D., Baker, I. T., Uliasz, M., Parazoo, N., Andrews, A. E., and Worthy, D. E. J.: A regional high-resolution carbon flux inversion of North America for 2004, Biogeosciences, 7, 1625-1644, doi:10.5194/bg-71625-2010, 2010.

Tan, Z., Lal, R., and Liu, S.: Using experimental and geospatial data to estimate regional carbon sequestration potential under no-till management, Soil Sci., 171, 950-959, 2006.

US Census Bureau: Population estimates - county characteristics, available at: http://www.census.gov/popest/counties/asrh, from the United States Census Bureau, Population Division, Washington DC, 2010.

USDA: Farm Resource Regions, Agricultural Information Bulletin 760, United States Department of Agriculture, Economic Research Service, Washington, DC, 2000.

USDA: ERS Bioenergy Information and Research, United States Department of Agriculture, Economic Research Service, Bioenergy Briefing Room, 2007.

USDA: Food availability data, available at: http://www.ers.usda. gov/data/foodconsumption, from the United States Department of Agriculture, Economic Research Service, Washington, DC, 2009a.

USDA: Feed grains database: yearbook tables, available at: http: //www.ers.usda.gov/Data/Feedgrains, from the United States Department of Agriculture, Economic Research Service, Washington, DC, 2009b.

USDA: Data and Statistics, United States Department of Agriculture, National Agriculture Statistics Service, Washington, DC, 2010a. 
USDA: Per capita availability adjusted for loss, United States Department of Agriculture, Economic Research Service, Washington, DC, $2010 \mathrm{~b}$.

USDA: Table 31 - Corn: Food, seed, and industrial use, United States Department of Agriculture, Economic Research Service, Washington, DC, 2010c.

USDA: Oil crops yearbook, appendix table 8 - soybean oil: supply and disappearance by month, U.S., 2005/06-2008/09, United States Department of Agriculture, Economic Research Service, Washington, DC, 2010d.

USDA: Table 820, Agricultural exports and imports - volume by principal commodities, United States Department of Agriculture, Economic Research Service, Washington, DC, 2010e.

West, T. O., Brandt, C. C., Wilson, B. S., Hellwinckel, C. M., Tyler, D. D., Marland, G., De La Torre Ugarte, D. G., Larson, J. A., and Nelson, R.: Estimating regional changes in soil carbon with high spatial resolution, Soil Sci. Soc. Am. J., 72, 285-294, 2008.
West, T. O., Singh, N., Marland, G., Bhaduri, B. L., and Roddy, A.: The human carbon budget: An estimate of the spatial distribution of metabolic carbon consumption and release in the United States, Biogeochemistry, 94, 29-41, 2009.

West, T. O., Brandt, C. C., Baskaran, L. M., Hellwinckel, C. M., Mueller, R., Bernacchi, C. J., Bandaru, V., Yang, B., Wilson, B. S., Marland, G., Nelson, R. G., De La Torre Ugarte, D. G., and Post, W. M.: Net ecosystem exchange and net ecosystem carbon balance for croplands in the United States: Increasing geospatial resolution of inventory-based carbon accounting, Ecol. Appl., 20, 1074-1086, 2010. 